2019-05-04

\title{
HIDDEN HISTORIES AND LANDSCAPE ENIGMAS
}

\author{
Wells, Elizabeth $Y$
}

http://hdl.handle.net/10026.1/14478

10.1080/17540763.2019.1582434

photographies

Informa UK Limited

All content in PEARL is protected by copyright law. Author manuscripts are made available in accordance with publisher policies. Please cite only the published version using the details provided on the item record or document. In the absence of an open licence (e.g. Creative Commons), permissions for further reuse of content should be sought from the publisher or author. 


\section{HIDDEN HISTORIES AND LANDSCAPE ENIGMAS}

\section{Liz Wells}

To cite this article: Liz Wells (2019) HIDDEN HISTORIES AND LANDSCAPE ENIGMAS, photographies, 12:2, 177-193, DOI: 10.1080/17540763.2019.1582434

To link to this article: https://doi.org/10.1080/17540763.2019.1582434

\section{Published online: 07 Jun 2019.}

5 Submit your article to this journal

\section{Article views: 18}

View Crossmark data $₫$ 


\section{HIDDEN HISTORIES AND LANDSCAPE ENIGMAS}

Photographers investigate places, research detail and explore ways of conveying some sense of the atmosphere and significance of particular environments. Photographs reveal that which can be seen, their stillness inviting attention to detail that might otherwise be overlooked. Yet landscapes may offer few clues or traces of people and socio-political histories that characterize sites yet are not necessarily marked visually. Pictures evoke personal and cultural memory through suggesting experiences of place that transcend the limitations of visual documentation. Critically reflecting on photographic engagement with battlefields and sites of execution, this paper considers pictorial strategies intended to unearth hidden histories. It evaluates photo-methodologies and approaches to storytelling deployed by artist-photographers seeking to reveal historical sediments and, through referencing that which is known but may not be perceived, to invoke reflection on legacies of conflict. Examples include: Bleda y Rosa, Battlefields; Chloe Dewe Matthews, Shot at Dawn; David Farrell, Innocent Landscapes; Ori Gersht, The Clearing; Anthony Haughey, Disputed Territory; Bart Michiels, The Course of History. It is suggested that, despite ways in which vistas veil histories and photographs prioritize the visible, through the inter-relation of research, reflection and aesthetic tactics photography can suggest hidden histories and offer insights into landscape enigmas.

Sometimes a landscape seems to be less a setting for the life of its inhabitants than a curtain behind which their struggles, achievements and accidents take place.

John Berger ${ }^{1}$

Photographers explore sites, researching detail and exploring ways of conveying a sense of their atmosphere and significance. Yet pictures can only reveal that which can be seen, although their stillness invites attention to detail that might otherwise be overlooked. As Berger suggests, the land may give little away. For photographers concerned with questions of place and history the poetics of visual imagery and associated texts together articulate stories that invite audience engagement.

Wars are determined publicly and politically, but are also experienced personally in terms of death, injury and domestic trauma. Public histories are often hidden, especially where a site has been changed through new buildings. Likewise, memories 
may be kept private. It follows that extensive research necessarily underlies serious pictorial enquiry.

This paper considers photographic strategies intended to unearth and, more particularly, convey hidden histories relating to battles or sites of execution. It evaluates photo methodologies and approaches to story-telling deployed by artistphotographers seeking to reveal historical sediments and to invoke reflection on legacies of conflict. Meaning emerges from a combination of research, photographic method, image and context of viewing. Given the recent centenary of the First World War, 1914-1918, that given the extensive carnage that resulted is often popularly, and over-optimistically, termed "the war to end all wars", examples are drawn from European art photography. ${ }^{2}$ However, considerations relating to research methods and photographic strategies are more widely relevant thematically, historically and geographically.

Some battlefield images acquire iconic status. For instance, in "Valley of the Shadow of Death", by British photographer Roger Fenton, cannonballs suggest the carnage that must have occurred during the Crimean War, documented by him in 1855. In picturing soldiers deployed to fight, army officers and campsite scenes, his work indicates the scale of the military endeavour. Another iconic example, "Royalist Militiaman at the Moment of Death", made in 1936 by the Hungarian photographer Robert Capa, shows a Republican soldier apparently falling, having been shot during the Spanish Civil War. Military death is graphically depicted. There has been extensive debate as to whether this image was a set-up, but that pictures are staged does not detract from the symbolic force or the endurance of such imagery as indicators of the realities of battle. Indeed, pictures may suggest conflict through various means. For example, in his extensive project, Disputed Territory (1999-2005), Irish photographer Anthony Haughey explored territorial tensions in Bosnia, Kosovo and in Northern Ireland. The cartridges strewn on the ground (Figure 1) remind us of Fenton's iconic image, at the same time symbolizing the red, white and blue of the Union Jack, suggesting that this is Unionist territory.

Sites of battle or of military executions often figure as "late photography", that is, images made after an event. David Campany has proposed that, whilst images made after the fact contribute within the construction of history, they are not traces of occurrences so much as "the trace of a trace of an event". He suggests that such pictures distance us from emotional implications, numbing us through becoming, as Campany puts it, "an undertaker, summarizer or accountant". Late photography can seem mute, animated only through familiarity with stories and contexts. Arguably this is photography at its most dispassionate and cerebral. Nevertheless, in all the examples discussed here, the photographer's aim is to affect us, to remind us to reflect on the human implications of what once occurred.

Places are defined through stories told and those yet to come. Through investigation and documentation of that which can be seen, photography makes a key contribution to storying locations. ${ }^{5}$ Yet specific sites may give little away; histories are not necessarily manifest visually. The methodological and aesthetic challenge for photographers is to transcend the limitations of the literalness of the camera, to find ways of alluding to that which has occurred through depiction of sites not as they 


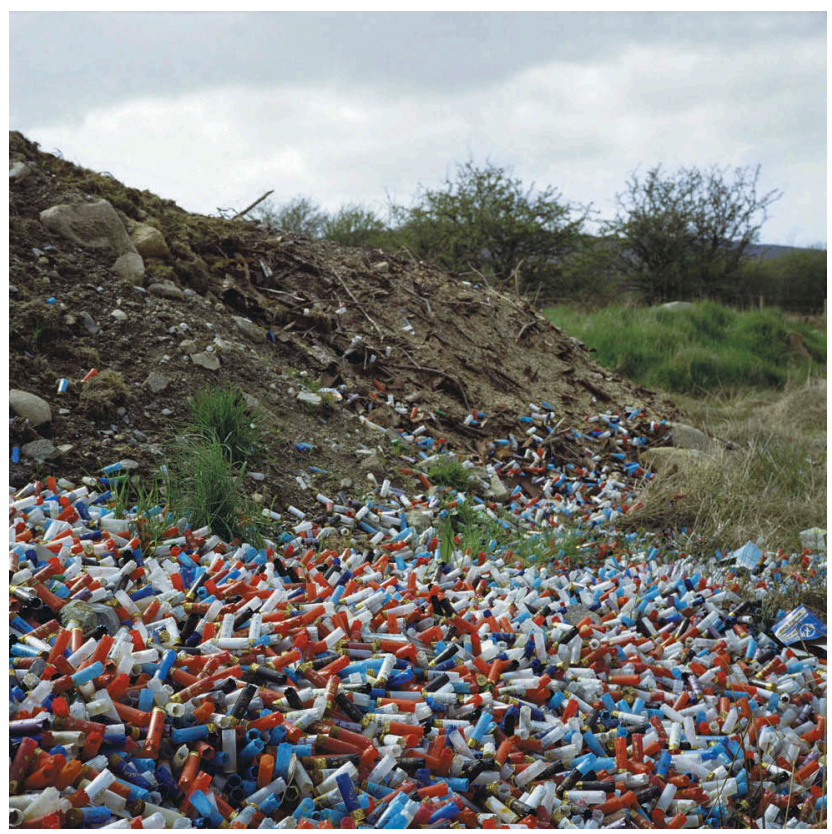

Fig. 1. Anthony Haughey, "Shotgun cartridges, Armagh/Louth Border", from the series Disputed Territory, 2006 (C) Anthony Haughey.

once were, but in terms of their appearance now, perhaps also suggesting something of ways in which a location has morphed into what can now be seen, whilst also referencing events that are no longer visible. Vistas may be enigmatic. As John Berger suggests, landscapes may veil the struggles of those who once lived or fought there. At the same time, in cases of relatively recent events, images may re-animate or rearticulate family memories (for instance, for British military personnel formerly stationed in the north of Ireland, or for their relatives and friends).

In their extensive research into historic battlefields in Spain, Europe and "Ultramar" (across the sea), Maria Bleda and José Maria Rosa search out traces of human activity in public locations (Figure 2). Their motivation is akin to visual anthropology; they seek to reveal and draw attention to that which might not otherwise be observed. Their interest in battlefields was kindled initially by "La Batalla de Almansa", 1709, an epic painting based on a battle that had occurred two years previously. ${ }^{6}$ Unlike history painting, Bleda and Rosa are not concerned with dynamic depiction of specific events; they are interested in broader historical contexts. They note that wars in the Iberian Peninsula emerged from a challenge to the former hierarchical political order, one that reflected new liberal ideals. In this respect, their ambition relates to Michel Foucault's enquiry into The Archeology of Knowledge wherein he reflects not on what "knowledge" represents to us, but on the parameters, assumptions and founding principles that constitute, characterize and limit ways of thinking. ${ }^{7}$ Foucault's intention was to inform historical understanding 

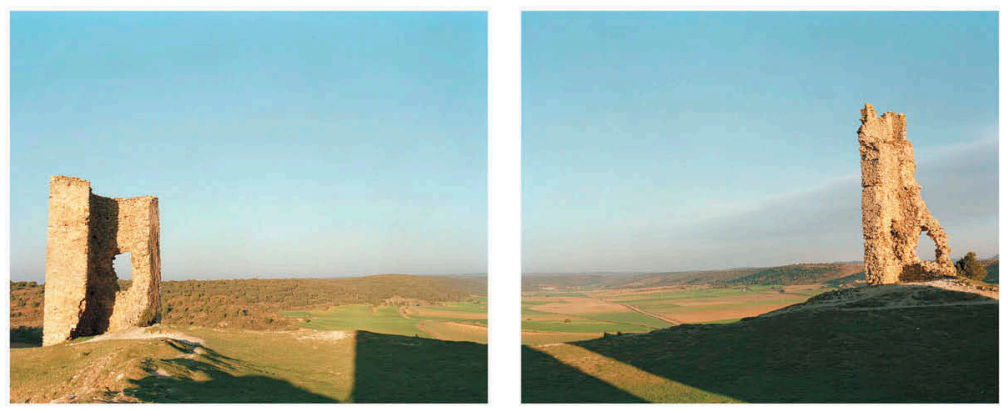

Calatanazazor, en torno al año 1000.

Fig. 2. Maria Bleda \& José Maria Rosa, "Calatañazor, en torno al año 1000", from Campos de batalla, España, 1994-96. (c) the artists.

through analysis of historical thought, or, as we might express it now, the cultural discourses that obtained in a specific place and era.

For Bleda y Rosa, landscapes are enigmatic yet have the potential to relate hidden histories, ones that they seek to unearth through photographic investigation and
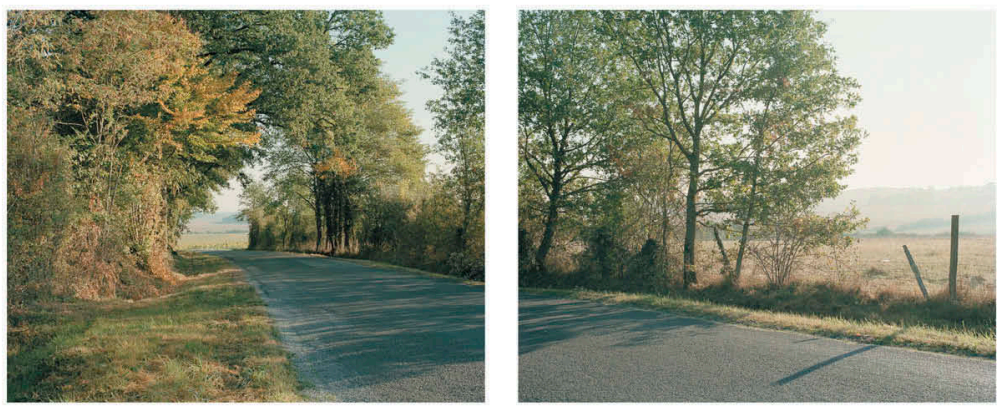

Fig. 3. Installation, Museo de Arte Contemporáneo, MARCO. Vigo, 2005. () the artists. 
contextual research. Their approach is archaeological in terms of investigating the layers of history that adhere to particular locations. It is epic in that each picture results from a journey researched and then made, whether travelling within Spain, Europe, Latin America or elsewhere. Preparation for each photograph involves attention to maps, engagement with local histories, reflection on broader socio-political histories, familiarizing themselves with issues that contextualized an event, making travel arrangements, acquiring any necessary permissions to access locations, determining photographic formats, film and equipment, and considering the light and weather conditions that they might encounter. ${ }^{8}$ Of course, this is common in land-oriented projects, but none the less represents intrepid navigation. Journeys become epic pilgrimages; each image represents a mission to find a location and to reflect on strategy; angle of vision, framing, light and tonal contrast contribute to conveying their interpretation of the mood of places. They adopt a rhetorical strategy that might be defined as academic picture-making, reflecting both the centrality of research in serious contemporary art photography and also longstanding traditions in narrative painting. As with any hermeneutic concern with theory, method and interpretation, the pleasures of viewing, of engaging with their enquiry, reside in part in reflecting on the limits of visible revelation; features of the lands may resist explanation, with surface characteristics shaped as a result of events lost from historical documentation or local memory. ${ }^{9}$

There are some indications of current use, for example, in Europe, the site of a territorial battle against an Islamic army of invasion now features a road linking the cities of Tours and Poitiers (Figure 3). Captions give locations, in some cases, evoking the history referenced. For instance, wire fencing that separates fields at Waterloo, Belgium, articulates current agricultural use with reference through the title, "Alrededores de Waterloo, 18 de junio de 1815", to the famous defeat of Napoleon's army by the British. The presence of farm labour is sometimes suggested, for example, there is a rough farm track and a windmill in the distance at Valmy, site of a civil conflict in September 1792 subsequent to the French Revolution. However, today's actual agricultural workers are as absent as those who died on the battlefields; we learn little about what is going on now, let alone what went on then.

Their first battlefield series was intended not only as an exploration of histories of place but also as a stand-in for philosophical and socio-political tensions that battles, as human struggles for or against power, almost always reflect. Battlefields are sites of events whose significance wanes over time, but that nonetheless represent historical turning points of greater or lesser significance. The works are presented as sets of diptychs. Central horizon lines unify two photographs within a single frame, $85 \times 150 \mathrm{~cm}$, constituting a panorama that, through the double width and the slight gap within each pair, suggests the openness of the spaces depicted whilst simultaneously drawing attention to the photographic act of selection, framing an image, and then re-framing for exhibition or publication (Figure 4).

In testifying to the former significance of locations, Bleda y Rosa's imagery might be taken as distanced substitutes for physical onsite commemoration. Late photographs act as traces dislocated both in terms of temporality but also phenomenologically since they are encountered in books and galleries, not at actual historical sites 


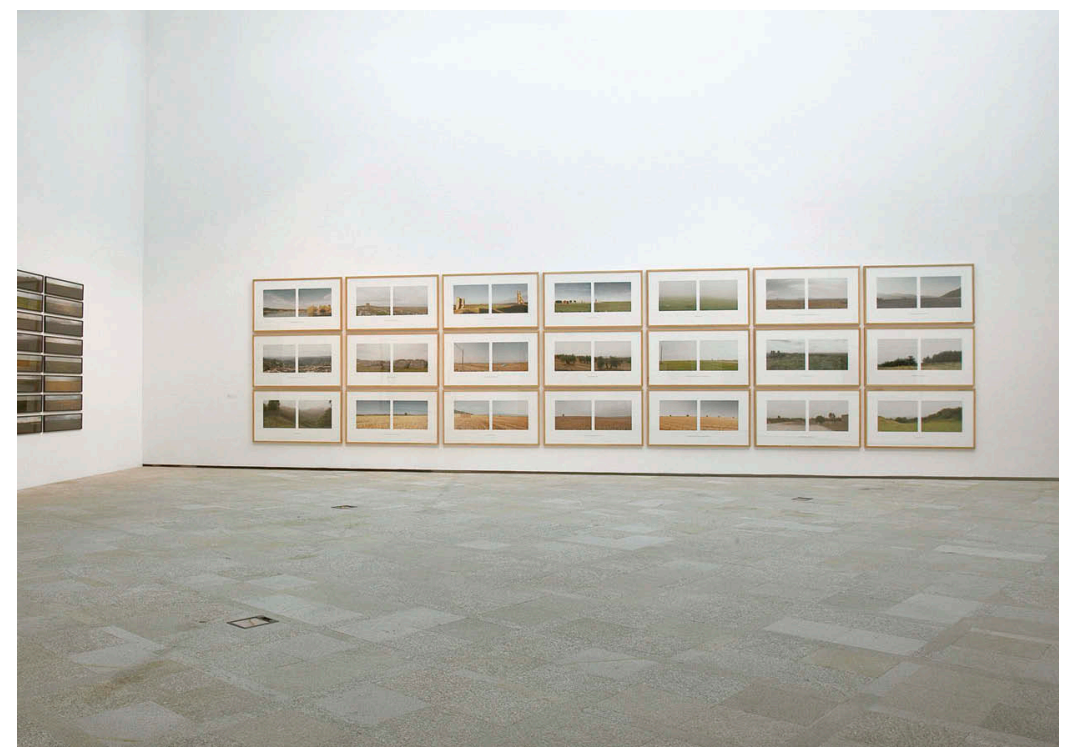

Fig. 4. Maria Bleda \& José Maria Rosa, "Entre Tours y Poitiers, 10 de octubre de 732", from Campos de batalla, Europe, 2010-12. (C) the artists.

of events. The reference is distanced, highly mediated as a means of seeing and telling.

What was at stake for earlier photographers — particularly for Roger Fenton given that he was sponsored by the British Royal Family — were ideological currencies such as military leadership and the (masculine) ideal of sacrifice for a greater common good such as "the nation", democracy, freedom. Recently, there has been a resurgence in interest in battles and battlefield, fuelled by the centenary anniversary of the First World War in Europe, within which notions of heroism and nationhood have been re-evaluated as questions to address. For example, British photographer Chloe Dewe Matthews authored Shot at Dawn, published in 2014 and based on an investigation of First World War sites in Belgium where British army deserters were killed. Her research involved archive investigations and site visits to identify places that had been used for shooting conscript soldiers, often very young (Figures 5 and 6). Identifying locations required a forensic approach to military and other sources of evidence, as well as researching subsequent social histories of usage. In a few instances, sites have been subject to development; it is uncomfortable to reflect on the disjunction between, on the one hand, the everyday use of the playground and classrooms at the primary school, Reningelst, West-Vlaanderen, and, on the other hand, the executions carried out there some 100 years earlier. Tensions emerge from the inter-relation of images that are often banal, and picture captions detailing dates of executions and the names of those shot. Many of the muted colour photographs depict unremarkable edges of fields, now perhaps agricultural areas. Silent landscapes. In visual terms the story-telling strategy is minimal; nothing 


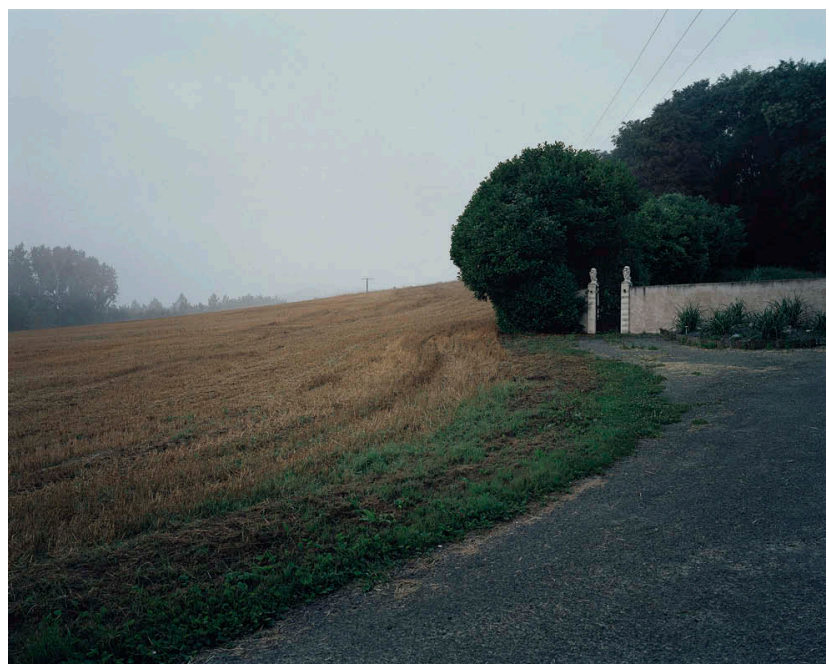

Fig. 5. Chloe Dewe Matthews, "Soldat Alphonse Brosse Soldat Jean Boursaud 07:00/10.10.1914 Ambleny, Aisne, Picardie", from Shot at Dawn, 2013. (C) Chloe Dewe Mathews.

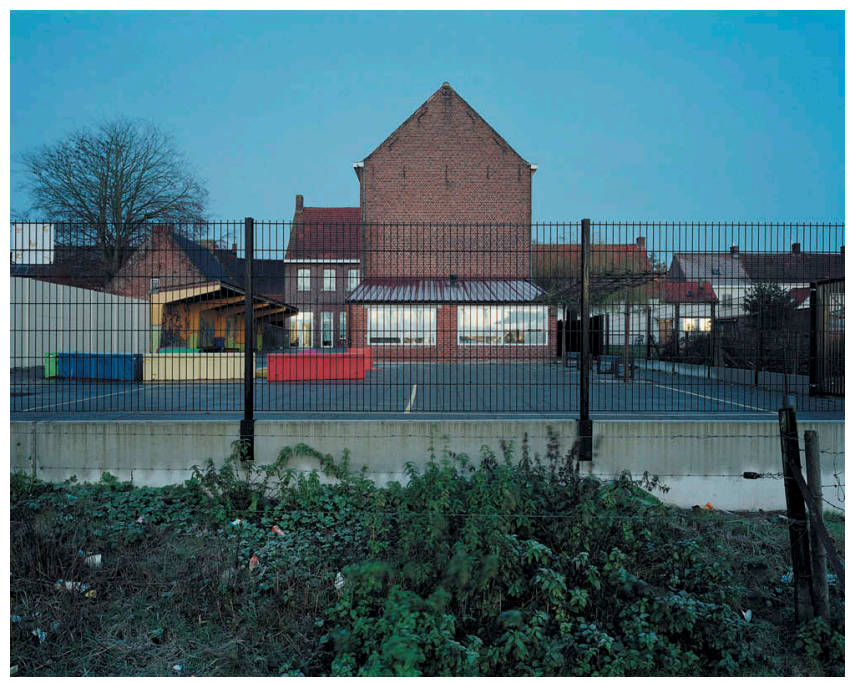

Fig. 6. Chloe Dewe Matthews, "Private William Smith 06:30/14.11.1917 Primary school, Reningelst, West-

Vlaanderen", from Shot at Dawn, 2013. ( C Chloe Dewe Matthews. Campos de batalla, Europe, 2010-12. ( ) the artists. 
in the pictures tells us what happened there. It is the series title and image captions that resonate, inviting reflection both on the brutality of executing conscripts for being scared or traumatized, and on the reluctance of land to reveal stories of what occurred. Given the heightened awareness that accompanies the First World War centenary within which the pictures were commissioned and first exhibited, her adoption of a relatively low-key strategy is effective, whereas it might be less so if encountered outside of this context. The imagery points to the disjunction between what we see and what should be known. It is timely in counteracting official war records within which such execution policies were not foregrounded - although wartime government records indicate that there was some awareness and questioning at the time. ${ }^{10}$ The series points to humanity's inhumanity.

As is evident from Dewe Matthews' strategy of listing the names and ages of those executed, inhumanity is perhaps more evident, or has more impact on us, when it is personalized, when victims are identified. But conflicts do not necessarily take the form of overt military battles; rather, agendas may be fought out within communities, for instance, in the late twentieth century era of the "Troubles" in Northern Ireland.

In May1999 the British parliament agreed "The Northern Ireland Location of Victims Remains Act" giving amnesty to those who could offer information about places where Catholics murdered by the IRA (Irish Republican Army) in the 1970s and early 1980s had been buried south of the border between Northern Ireland and the Irish Republic. David Farrell documented burial sites on the border between the six counties of the north of Ireland and the Irish Republic.

As the project title suggests, in Innocent Landscapes Farrell's focus was on the concealing of human histories. ${ }^{11}$ He was interested in the atmosphere of the "Sites of the Disappeared" and in the idea of landscapes disturbed by atrocity. He did not have to research locations; these had been made available via official investigation and the political process. His narratives commence with the roads to sites that had already been publicly identified (Figures 7). The images detail journeys, and ways in which previously undiscovered burial grounds had by then already been marked, for instance, through signs and fencing, or memorialized by friends and relatives, for example, with stones, flowers or pictures (Figures 8). Were it not for the particular historical context, the locations and testaments would seem banal; official barriers or personal commemorations that might be noticed in any rural area.

The six areas that he documented had revealed the bodies of eight men and one woman. The project was realized as a publication as well as through an exhibition. Each section of the photobook includes a map, broader location shots and memorial sites, all rural and otherwise banal. We view land in ordinary agricultural areas, that must have been disturbed in order to conceal, then disturbed again for excavation. How many people knew, we might wonder? Footprints and tyre tracks as well as stakes or fences now mark once hidden spots.

In contrast to the process of piecing together information to identify locations that characterized Chloe Dewe Matthews' research, these places had already been rendered visible, transformed into informal sites of commemoration. In terms of story-telling, Farrell had visual evidence with which to work. However, by contrast 


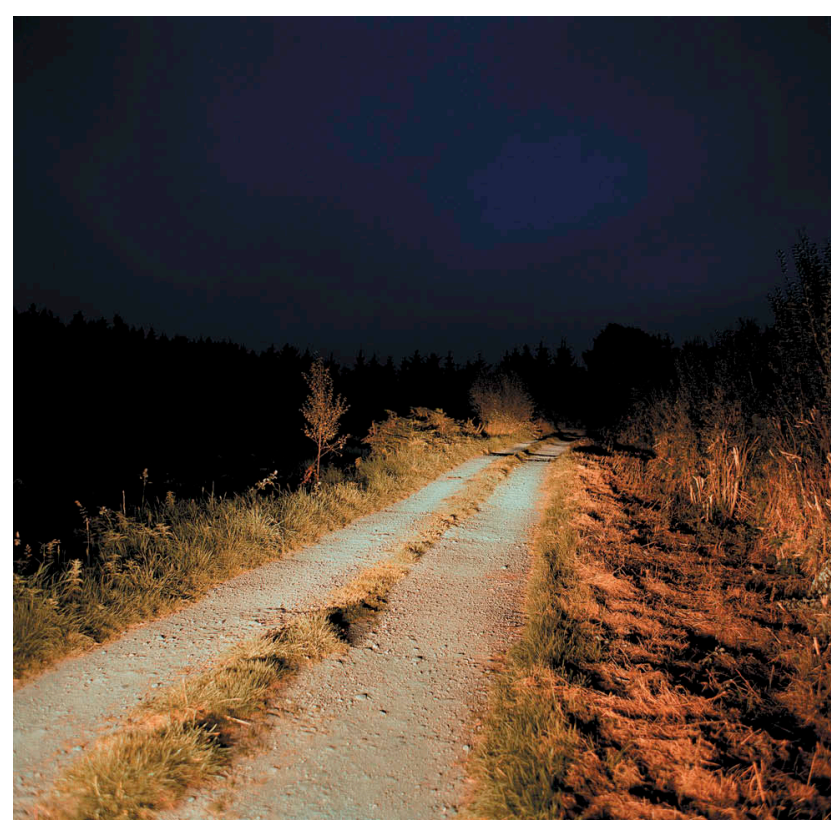

Fig. 7. David Farrell, Innocent Landscapes, Oristown (Twilight), 1999. @ David Farrell.

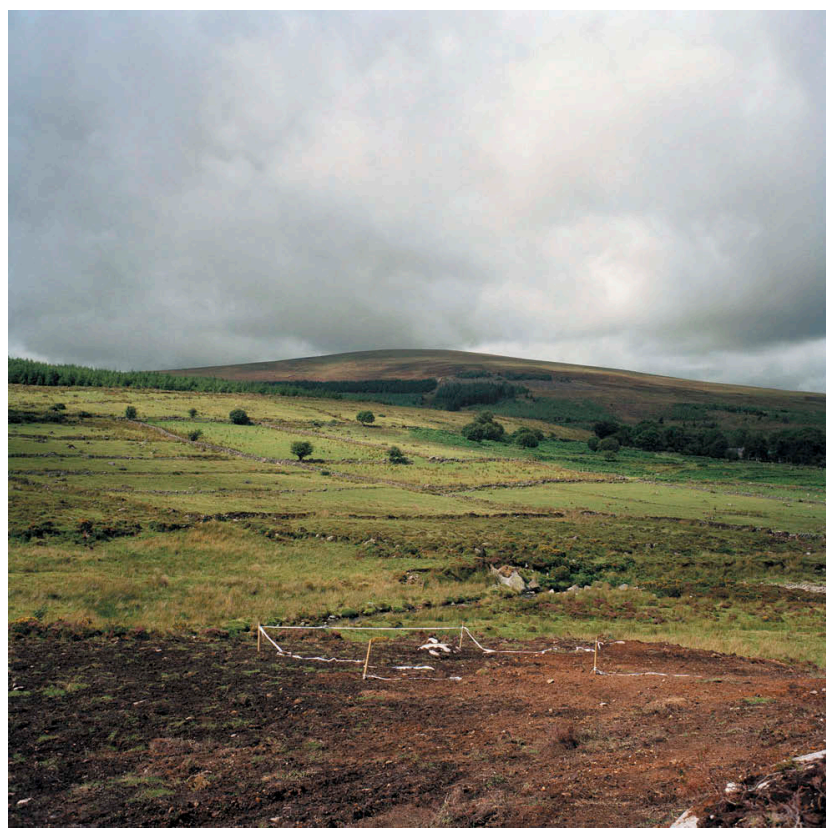

Fig. 8. David Farrell, Innocent Landscapes, Ballynultagh, 1999. @ David Farrell. 
with Dewe Matthews' investigations, these are recent events. Seeking further information or corroboration, for instance through oral histories relating to the perpetrators, would have been challenging; they occurred within living memory, with political and cultural tensions still in many respects unresolved. ${ }^{12}$

Dewe Matthews' use of archive materials lends documentary authority, as does Farrell's use of police sources and his inclusion of cartographic information alongside the visualizing of journeys to the various sites that, in this context, become his - and our — destinations. The project is disturbing not as a result of drama in the images themselves but in provoking reflection on deaths and disappearances, on the likelihood that people unknowingly walked across, worked or even picnicked in the fields, and on the impossibility of now ever visiting these locations without them offering silent and unnerving testimony to an exceptionally brutal history.

As becomes clear through juxtaposing the work of Bleda y Rosa with that of Dewe Matthews or Farrell, questions of historical proximity or distance are salient. Drawing upon historical records available to them, Dewe Matthews and Farrell offer more detailed investigative contextualisation wherein people and places are clearly identified. By contrast, Bleda y Rosa operate historically and conceptually from a more distanced perspective; their central interest is in the writing of history, in territoriality and in events that have been accorded significance through subsequent acknowledgement. It is the resonance of sites that once represented historical turning points, rather than the experience of individuals within conflict, that is their focus. The challenge that arises for evaluating visual representation in terms of aims and methodology is one of rendering investigations pertinent given — or despite — degrees of historical distance. For Foucault, this is manifest not through criticism of political reason at a macro level but through the more detailed analysis of processes and the manifestation of power relations in specific fields of experience. ${ }^{13}$ It follows that in critically reflecting on late photography, methodology and the tracing of traces of events, it is useful to distinguish between "battlefields" as a general concept, and "fields of battle", that is, sites that lend themselves to specific investigations wherein the focus is on the particularity of contexts, circumstances and events.

In pursuit of his project The Course of History, with its overall focus on fields of battle representing historical turning points, Belgian photographer Bart Michiels travelled extensively in Europe, including the Crimea (Ukraine) and Russia, and also in the Far East. Large-format colour photographs appear slightly muted as a result of flat grey or overcast skies that lend an ominous note to any reflections on sites of groundforce battles. He intended the series title to be ambiguous, remarking both the outcome of events and the teaching of history. Conceptually, and in terms of research, the project echoes that of Bleda y Rosa. Starting with limited information, each picture involved researching social and political histories in order to consider the significance of particular battles and to reflect on the political and military philosophies that contextualize events such as territoriality, heroism, cowardice and power hierarchies. Journeys to sites were sometimes epic in distance, planning and realization; they were also physical and tactile experiences. In viewing images and reading accompanying essays in photobooks, it is easy to forget that the photographer smelt the place, listened to sounds and felt the intensity of sunlight or damp. Conceptual approaches and emotional responses to actual sites are reflected aesthetically; artists determine different 
picture-making strategies. As already noted, Bleda y Rosa take a cool academic "look" at sites, working in diptychs that open up a space - metaphorically, a space for questions — in between pairs of images. By contrast, Michiels' work resonates operatically, primarily through the series title and the conceptual scale of the endeavour, but also through large exhibition prints $(152.4 \mathrm{~cm} \times 184.8 \mathrm{~cm})$ composed around a single viewing position. ${ }^{14}$ Relatively uniform image content within each picture suggests that we should stand back rather than examining detail. Michiels offers a scenario, a place, a date - and leaves viewers to consider the awesome implications, including the banality of actual places relative to their historical status. However, arguably the high-quality technical realization and the intention that the pictures should "speak for themselves" risk distracting from reflection on the human import of war.

Sometimes the symbolism lacks subtlety, for instance, windfall apples strewn across and rotting on the ground at "Passchendaele 1917, Goudberg Copse, 2005" in Belgium (Figures 9). Captions simply reference place, although the title The Course of History implies that these should be taken as historical turning points, as well as suggesting a certain relentlessness of wars as historical phenomena. The final section of the series takes us to Eastern European sites of trauma and destruction associated with the collapse of the Third Reich, and is named "Götterdämmerung". The reference to Wagner's opera infers the melodramatic, even though the visual resonances are subtle relative to the idea of turmoil and destruction suggested by this link. For instance, in "Stalingrad 1942, Volga I, 2008" two distant small red buoys, warnings maybe, are isolated in what appears to be a shallow river or bay (Figures 10), or in "Salamis 480BC, Cynosaura I, 2006" crumbling rocks at the edge of an expanse of water perhaps convey a dissolution of information about this battle, one that must have changed lives some two and a half millennia ago for reasons now lost in the mists of time. The series foregrounds battle locations as lyrical landscapes, rather than sites of human trauma.

Reflecting on genocide and the Second World War, Israeli-British photographer Ori Gersht deploys a lyrical but more explicitly rhetorical visual approach, using light as a primary means of signifying mood. He pictures woodlands and open spaces in Ukraine, sites of holocaust executions (Figures 11). The double meaning of the overall project title, The Clearing, is overt. The series includes a set of photographs, a video and a publication. In the pictures, misty skies and snow-covered fields metonymically suggest that something has been veiled over, an implication further emphasized through the sequencing of images wherein sites become increasingly indiscernible as snowy gloom intensifies or light turns to dusk. In his artist statement, he reminds us that blood literally stains the land through being incorporated into the soil then absorbed into the trees and vegetation that now thrive there. ${ }^{15}$ The visual rhetoric is dramatic, but some image titles are restrained: given the context: "Fallen Rocks", "Still Standing" or "Melt Down" are obviously metaphoric, but others such as "Red River" or "New Horizon" or "Galicia" merely suggest location.

The Forest depicts trees being felled, one by one (Figures 12). As the following statement makes clear, we hear the scrunching of leaves as they slowly crash to the ground, the tree felled at this site. ${ }^{16}$ 


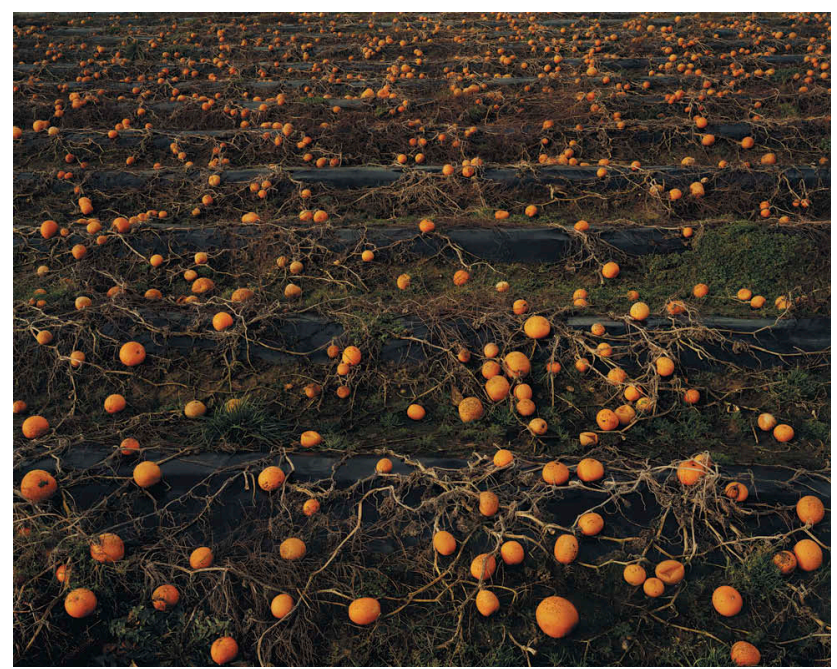

Fig. 9. Bart Michiels, "Passchendaele, 1917, Goudberg Copse, 2005", from The Course of History. (C) Bart Michiels and Robert Morat Gallery.

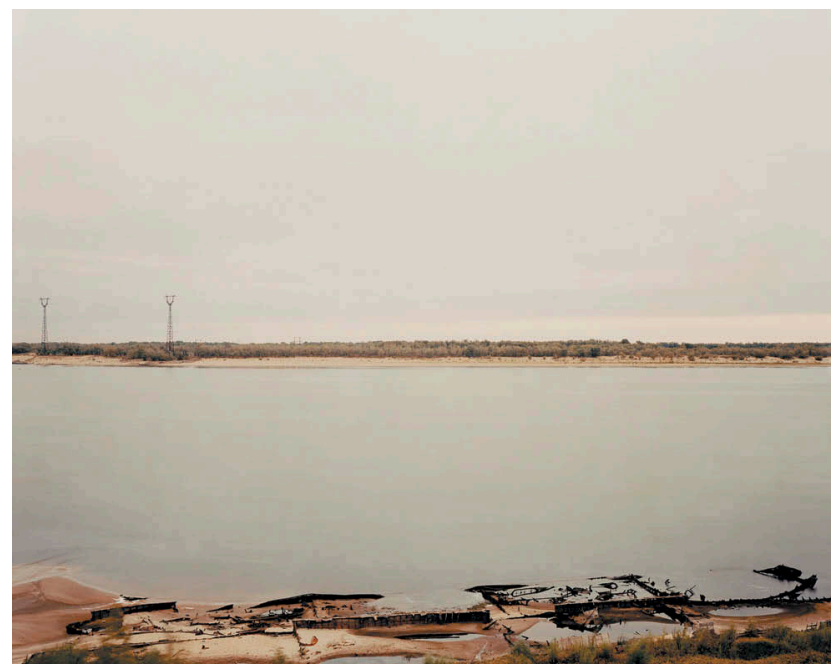

Fig. 10. Bart Michiels, "Stalingrad 1942, Volga I", 2008, from The Course of History. @ Bart Michiels and Robert Morat Gallery.

As the camera glides through the dense, sun-dappled forest, a tree falls heavily, and inexplicably, to the ground; and others soon follow, continuing out of shot, or heard but not seen. Afterwards, the silence of the place returns and, amongst so much that is still standing, we cannot be sure what we have just been witness to. Entranced by the hypnotic beauty of the projected image, then shocked by the ear-splitting sound of trees crashing to the ground, our immediate perception of 


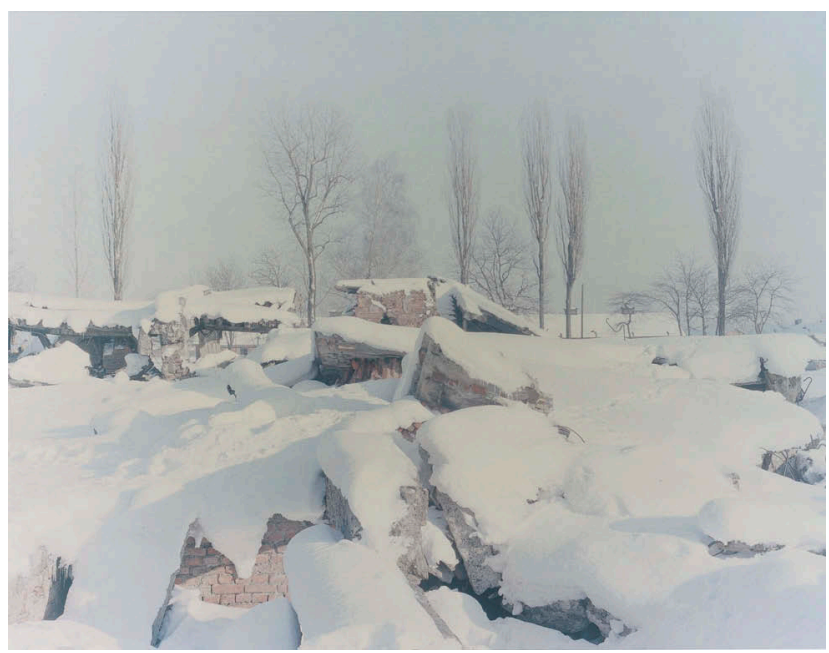

Fig. 11. Ori Gersht, "Fallen Rocks", from The Clearing: Liquidation, 2005. @) Ori Gersht.
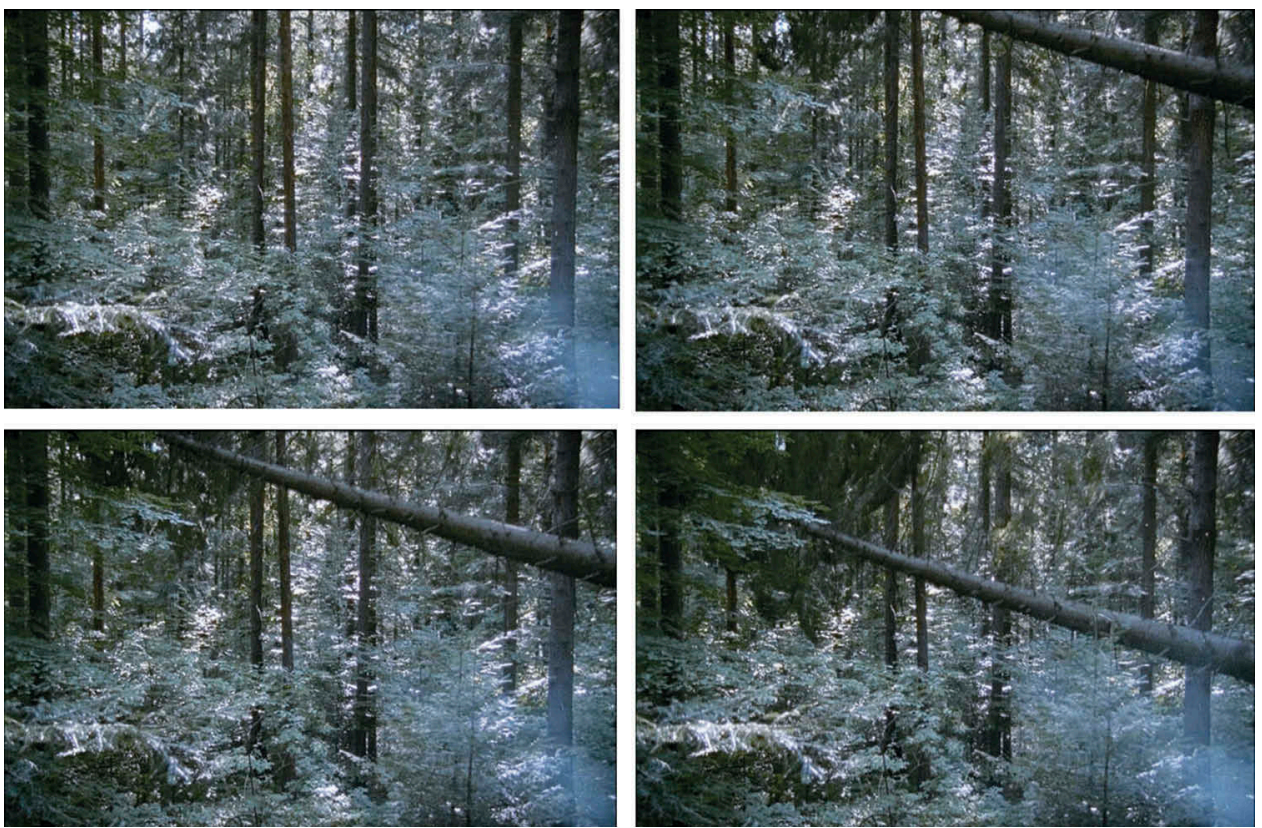

Fig. 12. Ori Gersht, stills from The Clearing: The Forest, 2005. Video, 14:40 minutes (filmed on $16 \mathrm{~mm}$.) ( Ori Gersht.

the place is challenged, forcing us to imagine what might have happened here before. $^{17}$ 


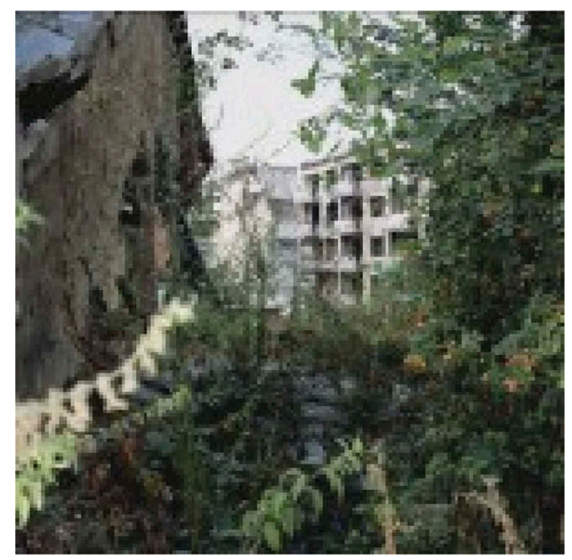

Fig. 13. Anthony Haughey, "Frontline Sarajevo," from the series Disputed Territory, 2006, @ Anthony Haughey.

The film was made in forests around Kosov, a site of a genocide (that included members of the artist's family). The film is emotionally moving and memorable; as a full-wall installation in a dark gallery space the experience is immersive. ${ }^{18}$ Given the double meaning of the overall exhibition and publication title, it becomes impossible to view the forest as anything other than tainted by history; the imagery stands in for mass murder, conveyed primarily through visual poetics. The drama emerges not only in the slowness of the process of falling but also in the uncannily hypnotic effect of the silence that follows the crashing of the tree and precedes a return of forest sounds.

The Forest has been related to the sublime, a response that provokes consideration of aesthetics and photographic strategies as a means of engaging audiences if the intention is to provoke reflection on issues. ${ }^{19}$ The sublime is often discussed in terms of fear or a sense of threat that is mitigated and transformed into a form of aesthetic pleasure through the distancing effect of, for instance, engaging with paintings representing circumstances rather than with actual life-threatening events. Fear may be kindled, but we don't have to do anything about that which the narrative suggests. So, if Gersht's work, or Michiel's, provoke reference to the sublime, does this indicate a distancing from the complexity of emotions and questions that should result from engaging with their work? Yet if the gallery is a form of theatre within which resonance is articulated through installation and images perform informationally and affectively, the key issue is whether the research and historical understanding that inform such conceptually extensive investigations operates to mitigate against the emotional safety-net of the sublime.

As noted in the introduction to this paper, Irish documentary photographer Anthony Haughey has worked extensively in Kosovo and Bosnia, as well as in Ireland (Figure 13). Haughey recently returned to Srebrenica, Bosnia, with a view to tracing people whom he had met and places that he had visited when first there nearly 20 years previously. The intention was to explore legacies of the conflict, and 
also to reflect on processes of realignment and reconciliation that characterize the aftermath. Rather than work with single images and photographic series, he created what he terms an "experimental documentary" video, Unresolved, 2015. ${ }^{20}$ Using moving image, with sound and extracts from interviews, allows him to tackle the challenge of conveying the complexity of circumstances within which there are many histories, many affiliations, and many sides to every story. The video includes eyewitness reports of massacres, and draws on Human Rights Watch archives as well as oral history, memories recounted to him on his research visits to the area, and the accounts of UN employees, Serb military officers and Dutch soldiers serving in Srebenica. In these respects, by contrast with, for instance, David Farrell's work on the internal Irish border, Haughey was able to access a range of memories and perspectives. Through moving image and audio, he could explore the complexities of this highly contested history, juxtaposing images and varying witness accounts in ways that the single image, or a photographic series, could not achieve. The voices of those whose friends and families did not survive, juxtaposed with archive footage, are memorable. The time-based narrative of video, whether minimal yet allegorical, as in Gerscht's The Forest, or complex in conveying contradictory histories, generates emotional response along with critical reflections. In other words, although their approaches differ, as photographers both Haughey and Gerscht effectively deploy the — literally and emotionally "moving" — effects and affects of narrativity.

Photography is an inherently visual medium; photographers centrally explore and respond to the visible. The challenge for photographers interested in investigating and drawing attention to invisible histories is one of unearthing evidence and indicating that which cannot be seen; of piercing the silence of the land. In the case of fields of battle and sites of execution, there is the additional issue of exploring strategies for conveying complex socio-economic events and consequences, from the failures of political negotiation that result in military engagement to processes of memorialization and reconciliation. If landscape veils histories, then the possibility of fuller historical reference relies on the effects and expressivity of aesthetic style as well as on titles, captions and artist statements, and on photographers' confidence in the curiosity of audiences willing to engage with imagery as touchstones provoking reflection.

War is endemic to history, as are hidden histories and forgotten narratives. Stories are often invisible, which for photographers represents a challenge in terms of aesthetic strategies since they can only record what is manifest visually. This is not merely a question of what is pictured, but also how it is pictured, what can be revealed, and of the inter-relation of visual and other materials. History might not be of our own making, but photographic research can foster ways of seeing that invite us to reflect upon the implications of what once occurred. Landscape enigmas speak not only in terms of the past.

\section{Disclosure statement}

No potential conflict of interest was reported by the author. 


\section{Notes}

1. Berger and Mohr, A Fortunate Man, 13.

2. The anniversary has attracted attention from many artist-photographers and curators in the UK and elsewhere. UK exhibitions included Conflict, Time, Photography at Tate Modern, 2014/2015, or No-Man's Land, Impressions Gallery, Bradford and on tour, 2017/2019. UK-based artist projects include Susan Trangmar's film, UNFOUND, 2016, that resulted from a commission by the French photographic artist agency Diaphane to make work in response to the Battle of the Somme, summer 1916 (see photographies 12.1, 2019) or, indeed, Shot at Dawn, by Chloe Dewe Mathews, discussed here, that was commissioned by the Ruskin School of Art, University of Oxford, and was included in both No Man's Land and the Tate Modern exhibition.

3. Haughey, Disputed Territory. Unionists, that is, Protestant militia, supported the north of Ireland remaining as part of the United Kingdom.

4. Campany, "Safety in Numbness," 9.

5. See, for example Tuan, Space and Place; Massey, For Space. Neither specifically discuss the contribution of photography, but the conceptual notion of places being "storied" offers a useful starting point for reflecting on the contribution of visual media.

6. "La Batalla de Almansa," 1709. Oil on canvas, $161 \times 390 \mathrm{~cm}$, painted by Buonaventure LIgli with the cartoonist Filippo Palotta. Prado Museum Collection, Madrid. In recounting a scenario, it is in the tradition of academic painting; it is also graphic in including very literal detail of men and horses engaged in fighting. Its original purpose was to tell a story, but viewed in the context of twenty-first century militarism, it invites us to reflect on the energy and manpower invested, on the slaughter of war, and, perhaps, to question notions of heroism implicated in fighting for principles, territory or nationhood.

7. Foucault, The Archeology of Knowledge.

8. My grateful thanks to the artists for detailed discussion of their preoccupations and work methods during a studio visit, Valencia, September 2016.

9. For instance, family stories, folk songs or myth.

10. Helen McCartney (2014) "Military Executions and Psychiatric Breakdown in the First World War," in Dewe Matthews, Shot at Dawn, np.

11. Farrell, Innocent Landscapes, 2001. The history had been a savage one of Catholic militia punishing individual members of the Catholic community.

12. Legacies of tensions in Ireland have been foregrounded once again in 2018 as the border between the north and the Republic of Ireland has provoked tensions within negotiations over the UK's proposed exit from the European Union. Farrell's publication, along with that of Anthony Haughey, offers a timely reminder of the consequences of tensions in the region.

13. Foucault, "Omnes et Singulatim."

14. The Shorter Oxford English Dictionary, 1993, defines "operatic" as "extravagantly theatrical" or "histrionic," that is, melodramatic and intended to attract attention.

15. Artist statement, The Photographers' Gallery, London, 2005.

16. Video, 14:40 minutes (filmed on $16 \mathrm{~mm}$ ). For a $1 \mathrm{~min} 24 \mathrm{sec}$ extract see http:// www.fvu.co.uk/projects/the-forest. 
17. Statement, Film and Video Umbrella, UK, 2005.

18. For example, as installed at The Photographer's Gallery, London, 2005.

19. http://spectrumphoto.co.uk/exhibition-review-on-ori-gersht-dont-look-back.

20. Unresolved, Dir. Anthony Haughey, 2015; experimental documentary, hdv col., Bosnia-Herzegovina, 17.22 mins. Extract, 3 mins, 10 secs, https://vimeo.com/ 169721280. The film marks the 20th anniversary of genocide in Srebrenica; in 1995 more than 8000 men and boys were systematically murdered by the Bosnian Serb army. The title (ironically) references UN Security Resolution 819, passed on 16 April 1993, that declared Srebrenica a "safe" area for refugees. Information courtesy of Anthony Haughey.

\section{References}

Berger, J., and J. Mohr. A Fortunate Man. London: Writers and Readers Publishing Cooperative, 1976. First pub., London: Allen Lane, 1967.

Bleda y Rosa. Campos de batalla. Valencia: Bombas Gens Centre d'Art, 2017.

Campany, D. "Safety in Numbness: Some Remarks on Problems of "Late Photography"." In Where Is the Photograph? edited by D. Green, 88-94. Brighton: Photoworks/ Photoforum, 2003.

Dewe Matthews, C. Shot at Dawn. Madrid: Ivory Press, 2014.

Farrell, D. Innocent Landscapes. Stockport: Dewi Lewis Publishing, 2001.

Foucault, M. The Archeology of Knowledge. New York: Pantheon, 1972.

Foucault, M. “Omnes Et Singulatim: Towards a Criticism of Political Reason.” 1979. Michel Foucault, Politics, Philosophy, Culture: Interviews and Other Writings 1977-1984. edited by L. D. Kritzman, 58-85. New York and London: Routledge, 1988.

Gersht, O. The Clearing. London: Film and Video Umbrella, 2005.

Haughey, A. Disputed Territory. Dublin: D.I.T., 2006.

Massey, D. For Space. London, Thousand Oaks and New Delhi: Sage, 2005.

Michiels, B. The Course of History. Bologna: Damiani, 2013.

Tuan, Y.-F. Space and Place: The Perspective of Experience. Minneapolis: Universty of Minnesota Press, 1977/2001.

Liz Wells is Professor in Photographic Culture, Faculty of Arts and Humanities, University of Plymouth, UK. She edited Photography: A Critical Introduction (2015, 5th ed.), The Photography Reader (2019, 2nd ed.) and The Photography Culture Reader (2019). Her publications on landscape include Land Matters, Landscape Photography, Culture and Identity (2011), and exhibitions she has curated include Light Touch, Baltimore Washington International Airport (February-June 2014); and Sense of Place, European Landscape Photography (BOZAR, Brussels, June-September 2012). She is series editor of Photography, Place, Environment (Bloomsbury Academic). 